\title{
Coronavirus disease (COVID-19) and conjunctival sac swab findings
}

Pavol Vesely', Elena Novakova², Michal Stubna ${ }^{3}$, Michal Trnka $^{4}$, Denisa Jurenova ${ }^{1}$, Darina Lyskova', Robert Furda ${ }^{5}$, Paulina Plesnikova ${ }^{1}$, Vratko Himic ${ }^{6}$ and Alena Furdova ${ }^{1 *}$ (i)

\begin{abstract}
Background: The purpose of this article is to evaluate the positivity of conjunctival sac swab by PCR (Polymerase chain reaction) test in COronaVlrus Disease 19 (COVID-19) patients.

Methods: Inclusion criteria of our study were COVID-19 patients hospitalized during March 2021 in inpatient wards at University Hospitals in towns Bratislava and Zilina, Slovakia. The conjunctival sac swabs collected by four ophthalmologists were stored for $24 \mathrm{~h}$, then analyzed in the laboratory of the Department of Microbiology and Immunology, Jessenius Faculty of Medicine in Martin, Comenius University, Slovakia. The sampling apparatus, used for conjunctival sac swab, was the Dacron polyester swab.

Results: We examined one group of 302 COVID-19 patients, 168 Male (56\%) and 134 Female (44\%). The patients' mean age was $66.3 \pm 13.66$ years, ranging from 25 to 96 years, and the mean length of hospital stay in our patients with a nasopharyngeal positive PCR test was $7.33 \pm 4.76$, from 2 to 24 days.

The PCR tests from the conjunctival sac swabs were positive in 33 patients (11\%), negative in 259 patients (86\%), and ten patients (3\%) were with the unclear result. In the group of 33 positive patients were 17 males with a mean age of $74.6 \pm 13.59$ years and 16 females with a mean age of $70.63 \pm 14.17$ years.

The cycle threshold $\left(C_{T}\right)$ values differed significantly between conjunctival sac swabs from the nasopharynx and the conjunctiva. Medians of the values were $25.1(14.1,32.1)$ and $31.5(22.6,36.6)(P<0.001)$, respectively.
\end{abstract}

Conclusion: This study affirmed that in COVID-19 patients the SARS-CoV-2 was detectable with PCR test in conjunctival sac swab, but the positivity rate was only about one to ten cases (11\%).

Keywords: COVID-19, Lacrimal apparatus, Analysis, Polymerase chain reaction

\section{Introduction}

COronaVIrus Disease 19 (COVID-19) is caused by the severe acute respiratory syndrome coronavirus-2 (SARS$\mathrm{CoV}-2)$. In the last 2 years, the disease has quickly become a worldwide health problem since its first detection in December 2019 in China [1].

Respiratory symptoms and myalgias are the fundamental clinical picture of COVID-19, but in addition, the conjunctivitis has been recognized as an additional

\footnotetext{
* Correspondence: alikafurdova@gmail.com

'Department of Ophthalmology, Faculty of Medicine, Comenius University, (Klinika oftalmológie LFUK a UNB), Hospital Ruzinov, Ružinovská 6, 82606 Bratislava, Slovak Republic

Full list of author information is available at the end of the article
}

clinical manifestation associated with SARS-CoV-2 infection $[2,3]$. In some studies in the past 2 years, the presence of SARS-CoV-2 Ribonucleic acid (RNA) in conjunctival sac and tears has also been reported in COVID-19 patients [4-7].

The primary routes of transmission of SARS-CoV-2 infection are the most frequent via respiratory droplets. The SARS-CoV-2 RNA has been also detected in tears and conjunctival sac from COVID-19 patients. Clinical symptoms, like conjunctivitis, can occur alongside the other COVID-19 symptoms, or it may be the only sign of the disease [7, 8]. The purpose of this article is to evaluate the positivity of conjunctival sac swab by PCR (Polymerase chain reaction) test in COVID-19 patients.

\section{Springer Open}

(๑) The Author(s). 2022 Open Access This article is licensed under a Creative Commons Attribution 4.0 International License, which permits use, sharing, adaptation, distribution and reproduction in any medium or format, as long as you give appropriate credit to the original author(s) and the source, provide a link to the Creative Commons licence, and indicate if changes were made. The images or other third party material in this article are included in the article's Creative Commons licence, unless indicated otherwise in a credit line to the material. If material is not included in the article's Creative Commons licence and your intended use is not permitted by statutory regulation or exceeds the permitted use, you will need to obtain permission directly from the copyright holder. To view a copy of this licence, visit http://creativecommons.org/licenses/by/4.0/. 


\section{Materials and methods}

We investigated 302 patients with the clinical diagnosis of COVID-19 and the combination of clinical symptoms that included positive nasopharyngeal RT-qPCR test. The clinical symptoms have been confirmed from the patient records, by including the ocular symptoms.

Inclusion criteria of our study were the COVID-19 patients hospitalized during March 2021 in inpatient wards at University Hospitals in towns Bratislava and Zilina, Slovakia. The conjunctival sac swab was analyzed by PCR test. The sampling apparatus was the Dacron polyester swab with the NADAL ${ }^{\bullet}$ COVID-19 IgG/IgM (Nal von Minden $\mathrm{GmbH}$, Moers, Germany) sample. The conjunctival sac swabs were collected by four ophthalmologists and stored for $24 \mathrm{~h}$. On the next day, the analysis was performed in a laboratory of the Department of Microbiology and Immunology, Jessenius Faculty of Medicine in Martin, Comenius University, Slovakia.

\section{RNA isolation}

RNA isolation from the conjunctival sac swabs with the concentrated virus was performed using a Quick-RNA ${ }^{\text {тм }}$ Viral 96 kit (Zymo Research, Waltham, MA, USA, cat\#R1041) isolation kit, as recommended by the manufacturer, with a slight modification: $200 \mu \mathrm{l}$ of DNA/RNA Shield TM was added to $200 \mu$ of transport medium containing the conjunctival sac swab. These conjunctival sac swabs were then mixed with viral RNA buffer and transferred to a Zymo-Spin ${ }^{\text {Ts }}$ I-96 Plate. After washing and centrifugation, viral RNA was transferred with $25 \mu \mathrm{l}$ DNase/RNae-free water to the elution plate and then used in an RT-qPCR test.

\section{RT-qPCR test}

We used the Multiplexed rTest set (rTEST COVID19/ FLU qPCR Kit) from MultiplexDX ${ }^{\mathrm{sm}}$ International, according to the manufacturer's requirements. This kit is a re-designed version of the WHO (World Health Organization) recommended Charité, Berlin protocol, along with a newly designed differential test that can distinguish between SARS-CoV-2, IAV (Influenza A Virus) and IBV (Influenza B Virus). RT-qPCR was performed on qTOWER ${ }^{3}$ (Analytic Jena GmbH, Jena, Germany) with standard Thermal Cyclers. The viral load in the initial conjunctival sac swab was estimated by specifying the threshold cycle $\left(\mathrm{C}_{\mathrm{T}}\right)$ of the SARS-CoV-2. The results were analyzed using qPCRsoft (real-time PCR control and evaluation software) with a constant threshold calculation for the determination of $\mathrm{C}_{\mathrm{T}}$ values.

\section{Statistical analysis}

Continuous variables were expressed as means \pm standard deviations, and categorical variables as frequencies and percentages. Comparisons of means between groups were performed using a paired t-test for normally distributed continuous variables. All tests were carried out at the significance level of $\alpha=0.001$. (The two-tailed $p$ value of $<0.001$ was considered statistically significant.) Data analysis was conducted by the statistical software IBM SPSS version 27 (IBM SPSS Inc., Armonk, NY, USA).

\section{Results}

In 302 patients, we examined, the median age was $66.3 \pm 13.66$ years (Table 1), ranging from 25 to 96 . From the group, 168 patients were males with the median equal to 63.5 years and the mean $64.95 \pm 13.88$ years, and 134 female patients with the median equal to 69.0 years and the mean $68.01 \pm 13.23$ years. To specify the status of the patients in inpatient care, there 262 patients (93\%) were on nonmechanically ventilated oxygen therapy and 13 patients $(4.3 \%)$ were on mechanically ventilated oxygen therapy, 24 h a day.

The PCR tests from the conjunctival sac swabs were positive in 33 patients (11\%), negative in 259 patients $(86 \%)$, and ten patients $(3 \%)$ were with the unclear result. In the group of 33 positive patients were 17 males with a mean age of $74.6 \pm 13.59$ years and 16 females with a mean age of $70.63 \pm 14.17$ years. To specify the status of the patients in inpatient care, there 31 patients were on nonmechanically ventilated oxygen therapy and two patients were on mechanically ventilated oxygen therapy, $24 \mathrm{~h}$ a day.

Ocular symptoms (itching and red eye) were documented in 52 patients $(17 \%)$ - for the details see the Table 1 and the Table 2.

Table 1 The group of all COVID-19 patients and its subgroup with positive PCR test in conjunctival sac swab

\begin{tabular}{lllllll}
\hline Gender & No & Age $^{\mathbf{a}}$ & $\begin{array}{l}\text { Nonmechanically ventilated } \\
\text { patients }^{\mathbf{b}}\end{array}$ & $\begin{array}{l}\text { Mechanically ventilated } \\
\text { patients }\end{array}$ & $\begin{array}{l}\text { Positive conjunctival sac } \\
\text { swab }\end{array}$ & $\begin{array}{l}\text { Ocular } \\
\text { symptoms }\end{array}$ \\
\hline Female & 134 & $\begin{array}{l}68.01 \pm \\
13.23\end{array}$ & $116[15]$ & $8[1]$ & 16 & $20[1]$ \\
Male & 168 & $\begin{array}{lll}64.95 \pm \\
13.88\end{array}$ & $146[16]$ & $5[1]$ & 17 & $32[3]$ \\
Overall & 302 & $\begin{array}{lll}66.30 \pm \\
13.66\end{array}$ & $262[31]$ & $13[2]$ & 33 & $52[4]$
\end{tabular}

${ }^{a}$ Mean (in years) and Standard Error of Mean (SEM) were calculated, and were showed as Mean \pm SEM

${ }^{\mathrm{b}}$ Patients [Patients with positive PCR test in conjunctival sac swab] 
Table 2 The comparison of the number of all COVID-19 patients with the subset of those who were with positive PCR test in conjunctival sac swab stratified by age and gender

\begin{tabular}{|c|c|c|c|c|c|}
\hline Age group & Female $^{a}$ & Male $^{\text {a }}$ & Nonmechanically ventilated patients ${ }^{b}$ & Mechanically ventilated patients ${ }^{b}$ & Ocular symptoms $^{b}$ \\
\hline 20 & $1[0]$ & $1[0]$ & $1[1]$ & $0[0]$ & $0[0]$ \\
\hline 30 & $3[0]$ & $5[0]$ & $2[5]$ & $0[0]$ & $0[0]$ \\
\hline 40 & 11 [2] & 18 [1] & 7 [14] & $2[0]$ & $1[6]$ \\
\hline 50 & 16 [2] & 38 [1] & $11[32]$ & $3[2]$ & $4[6]$ \\
\hline 60 & $44[3]$ & $45[4]$ & 42 [33] & 1 [3] & 8 [10] \\
\hline 70 & 35 [5] & 35 [5] & 30 [35] & $2[0]$ & $5[5]$ \\
\hline 80 & 22 [3] & 21 [3] & $21[21]$ & $0[0]$ & $2[5]$ \\
\hline 90 & $2[1]$ & $5[3]$ & $2[5]$ & $0[0]$ & $0[0]$ \\
\hline
\end{tabular}

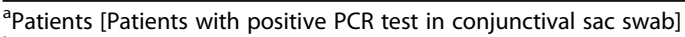

${ }^{\mathrm{b}}$ Female [Male]

In Fig. 1, we compare all COVID-19 positive patients, grouped by age and gender, and its subgroup with positive PCR test in conjunctival sac swab.

In Table 2 we document male and female patients in the age groups at ten-years intervals, where, for example, the 20 years age group represents the interval from 20 to 29 years.

The cycle threshold $\left(\mathrm{C}_{\mathrm{T}}\right)$ values varied significantly between conjunctival sac swabs from the nasopharynx and conjunctiva, with a median value of $25.1(14.1,32.1)$ and $31.5(22.6,36.6)(P<0.001)$, respectively (Table 3$)$. The cycle threshold $\left(C_{\mathrm{T}}\right)$ values between nasopharynx and conjunctiva were different for all patients when stratified by age and gender (Table 4 ).

\section{Discussion}

The similar study of Kumar et al. [7] shows that SARS$\mathrm{CoV}-2$ can be detected in conjunctival swabs in patients with confirmed COVID-19 disease. In their results, the positivity rate of detecting SARS-CoV-2 in conjunctival swabs was low, there only one patient $(2.23 \%)$ out of the group of 45 patients was positive, none of the patients had any ocular symptoms, and the patient's cycle threshold value in conjunctival swab was 33, for the real-time RT-PCR SARS-CoV-2. In our study, we investigated more than six times more patients, the positivity in conjunctival sac swab was more than four times higher (11\%), we found ocular symptoms (itching and red eye) in 52 patients (17\%), and patients, who were also divided into age groups at ten-years intervals, the cycle threshold values were significantly different between the conjunctival sac swabs from the nasopharynx and conjunctiva, with median value of 25.1 and $31.5(P<0.001)$, respectively. The $C_{\mathrm{T}}$ values between nasopharynx and conjunctiva were different for all patients when stratified by age and gender in our group.

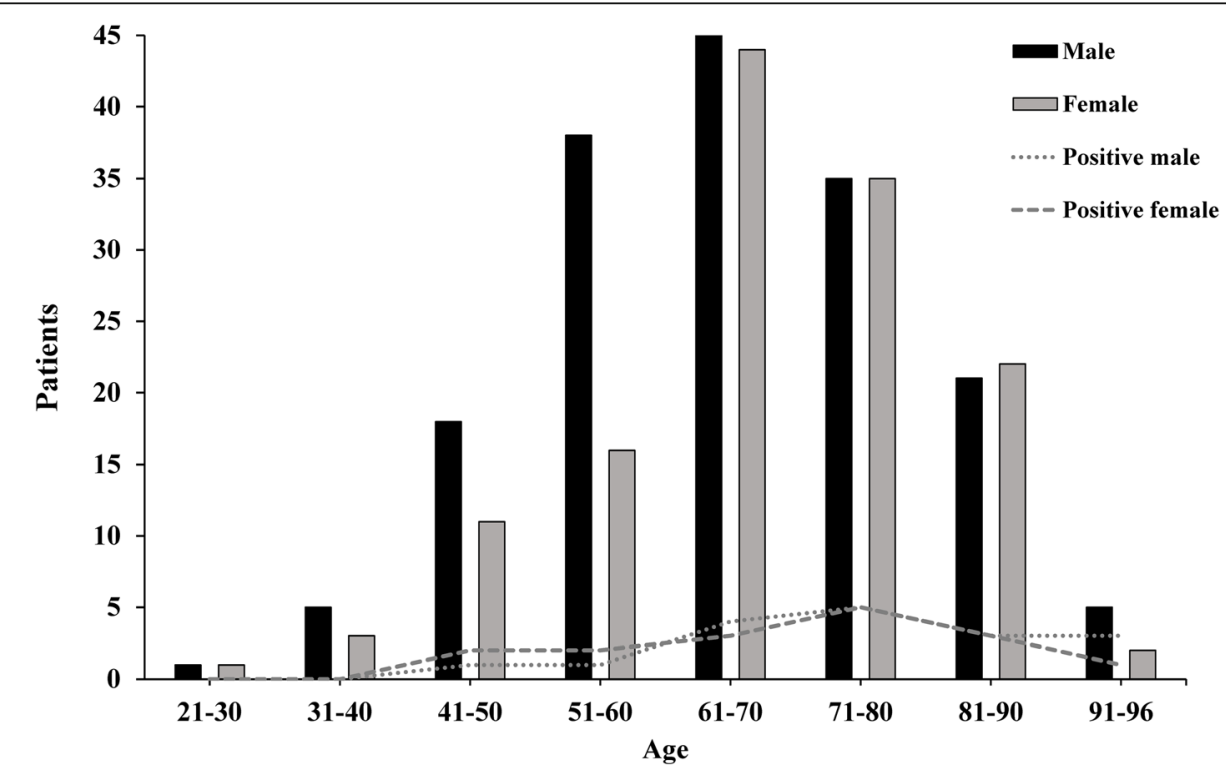

Fig. 1 The numeric comparison of all COVID-19 patients, by age and gender, and the subgroup with positive PCR test in conjunctival sac swab 
Table 3 The cycle threshold $\left(C_{T}\right)$ values from patients with positive PCR test in conjunctival sac swab

\begin{tabular}{lclll}
\hline Patients & No & $\begin{array}{l}\boldsymbol{C}_{\boldsymbol{T}} \text { value in } \\
\text { nasopharynx }\end{array}$ & $\begin{array}{l}\boldsymbol{C}_{\boldsymbol{T}} \text { value in } \\
\text { conjunctiva }\end{array}$ & $\boldsymbol{p}$ \\
\hline Female & 16 & $23.58 \pm 5.53$ & $31.44 \pm 3.92$ & $<0,001$ \\
Male & 17 & $23.38 \pm 4.73$ & $29.91 \pm 3.31$ & $<0,001$ \\
Overall & 33 & $23.48 \pm 5.06$ & $30.65 \pm 3.64$ & $<0,001$ \\
\hline
\end{tabular}

${ }^{a}$ Mean and Standard Error of Mean (SEM) were calculated, and were showed as Mean $\pm \mathrm{SEM}$

SARS-CoV-2 obtains passage via angiotensinconverting enzyme 2 (ACE-2) receptor, which may express in various tissues, including the conjunctiva [9]. During the SARS-related coronavirus flare-up in 2003, an investigation showed that medical personnel experienced a more significant danger of SARS contamination when there was an unprotected eye-to-eye connection with discharges. There is an increasing trend in reports indicating that some COVID-19 pneumonia cases began with conjunctivitis as an underlying feature after contact with infected individuals. Detection of viral RNA by RTqPCR can be valuable in the early detection of COVID19 and in taking appropriate isolation measures. Then, determining whether SARS-CoV-2 is transmissible by contacting the conjunctival sac importantly considers that warrants investigation [10-12].

SARS-CoV-2 RNA has recognition in tears of patients with COVID-19 both with and without conjunctivitis. Be that as it may, gathering tears and visual discharges for SARS-CoV-2 detection appears to have limited benefit $[13,14]$.

During the COVID-19 pandemic, more authors published reports highlighting various ocular signs of the infection. One meta-analysis discovered that the general preponderance of ocular symptoms was around 11\% [15]. The most frequent eye symptoms in COVID-19 patients were ocular pain, redness, and follicular conjunctivitis. Based on the current studies, SARS-CoV-2 we can verify by swab in conjunctival secretion when analyzing it with RT-PCR. In our approach, we found 33 positive patients (11\%).
Only a few authors have suggested utilizing eye protection to evade the projected transmission of COVID19. These proposals incorporate techniques to forestall transmission of disease among ophthalmologists and optometrists. They are produced from ocular systems, for example, during cataract surgery and non-contact tonometry [16-21].

The data of one study with meta-analysis uncovered the extent of different visual features, for example, visual acuity decline, redness, release, and follicular conjunctivitis. Another study announced similar ocular symptoms. In addition, these studies depended on itemized and comprehensive surveys and patient meetings, which occurred a few days after the patients left the medical inpatient clinic $[21,22]$. Subsequently, the information from the examinations could be subject to the bias of review inclination. Likewise, it isn't sure whether these visual features preceded COVID-19 or happened as a consequence of that. For example, symptoms like dry eyes, tingling, and foreign body sensation might be profoundly normal in every COVID-19 patient. Also, certain studies have included healthcare workers who might be more sharpened on detailing different indications. Then again, in dangerous circumstances, the more extreme clinical indicators may overshadow ophthalmic symptoms, which may go unnoticed. In addition, the studies raised the worry that COVID-19 can have the ocular manifestations (explicitly follicular conjunctivitis) as first and in various cases the single symptom of the disease. Pooled information from three investigations in the meta-examination uncovered that the visual side effects might be the main look in roughly $2.2 \%$ of patients. It is essential to be aware of such cases and keep clinical suspicion of COVID-19 in such patients [21, 23-26].

In one systematic review, the authors compared over 200 ophthalmology-focused scientific articles with the COVID-19 pandemic they published during the last months, reporting the presence of conjunctivitis and other varied ocular manifestations [27]. Our results contributed to this rapidly growing topic.

Table 4 The cycle threshold $\left(C_{T}\right)$ values from patients with positive PCR test in conjunctival sac swab stratified by age and gender

\begin{tabular}{|c|c|c|c|c|c|c|}
\hline \multirow{2}{*}{$\begin{array}{l}\text { Age } \\
\text { group } \\
\text { (years) }\end{array}$} & \multicolumn{3}{|c|}{ Female } & \multicolumn{3}{|c|}{ Male } \\
\hline & No & $C_{T}$ value in nasopharynx ${ }^{a}$ & $C_{T}$ value in conjunctiva ${ }^{a}$ & No & $C_{T}$ value in nasopharynx ${ }^{a}$ & $C_{T}$ value in conjunctiva ${ }^{a}$ \\
\hline 40 & 2 & $22.56 \pm 5.74$ & $32.49 \pm 0.66$ & 1 & $29.80 \pm 0.00$ & $33.54 \pm 0.00$ \\
\hline 50 & 2 & $20.45 \pm 7.85$ & $34.61 \pm 0.04$ & 1 & $25.00 \pm 0.00$ & $30.45 \pm 0.00$ \\
\hline 60 & 3 & $29.57 \pm 2.48$ & $31.92 \pm 2.97$ & 4 & $23.65 \pm 6.24$ & $30.03 \pm 4.14$ \\
\hline 70 & 5 & $23.63 \pm 5.51$ & $30.90 \pm 4.92$ & 5 & $22.28 \pm 5.16$ & $28.60 \pm 3.68$ \\
\hline 80 & 3 & $23.47 \pm 2.24$ & $31.99 \pm 2.35$ & 3 & $24.03 \pm 3.68$ & $30.45 \pm 3.19$ \\
\hline 90 & 1 & $14.00 \pm 0.00$ & $22.56 \pm 0.00$ & 3 & $21.51 \pm 4.78$ & $29.99 \pm 3.62$ \\
\hline
\end{tabular}

${ }^{\mathrm{a}}$ Mean and Standard Error of Mean (SEM) were calculated, and were showed as Mean \pm SEM 


\section{Conclusion}

In summary, manifestations like redness, pain, and conjunctivitis may occur in COVID-19 patients. This study confirmed that in COVID-19 patients, the SARS-CoV-2 can also be detected in conjunctival sac swab by PCR test. The positivity rate is only about one to ten cases (11\%). However, the detection speed of viral RNA from conjunctival sac swab and tear fluid with the PCR test is poor.

\section{Acknowledgements \\ Not applicable.}

\section{Authors' contributions}

Research design. PV, AF; Data acquisition: MS, MT, DJ, DL, PP; Data analysis: EN, MT, RF, VH; Manuscript preparation: MT, RF, AF. The author(s) read and approved the final manuscript.

\section{Funding}

Not applicable.

\section{Availability of data and materials}

The datasets used and/or analyzed during the current study are available from the corresponding author on reasonable request.

\section{Declarations}

\section{Ethics approval and consent to participate}

This submission complies with the guidelines for human studies and animal welfare regulations. The study adhered to the guidelines by Helsinki declaration This paper does not involve any experimental drug(s) that does not have FDA approval.

The treatment of the subject described in this paper was carried out after obtaining written informed consent that was taken from all patients and is stored in the patient's record.

\section{Consent for publication}

Not applicable.

\section{Competing interests}

No conflicting relationship exists for any author.

\section{Author details}

${ }^{1}$ Department of Ophthalmology, Faculty of Medicine, Comenius University, (Klinika oftalmológie LFUK a UNB), Hospital Ruzinov, Ružinovská 6, 82606 Bratislava, Slovak Republic. ${ }^{2}$ Department of Microbiology and Immunology, Jessenius Faculty of Medicine in Martin, Comenius University, Bratislava, Slovakia. ${ }^{3}$ Department of Ophthalmology, Hospital Zilina, Zilina, Slovakia. ${ }^{4}$ Department of Medical Physics, Biophysics, Informatics and Telemedicine, Faculty of Medicine, Comenius University, Bratislava, Slovakia. ${ }^{5}$ Department of Information Systems, Faculty of Management, Comenius University in Bratislava, Bratislava, Slovakia. ${ }^{6}$ Department of Physiology, Anatomy and Genetics, University of Oxford, Oxford, UK.

Received: 9 October 2021 Accepted: 2 February 2022

Published online: 19 February 2022

\section{References}

1. Sohrabi C, Alsafi Z, O'Neill N et al (2020) World Health Organization declares global emergency: a review of the 2019 novel coronavirus (COVID-19). Int J Surg 76:71-76. https://doi.org/10.1016/j.jjsu.2020.02.034

2. Li S, Li D, Fang J, Liu Q, Cao W, Sun X, Xu G (2021) SARS-CoV-2 receptor ACE2 is expressed in human conjunctival tissue, especially in diseased conjunctival tissue. Ocul Surf 19:249-251. https://doi.org/10.1016/j.jtos.2020. 09.010

3. Coroneo MT (2021) The eye as the discrete but defensible portal of coronavirus infection. Ocul Surf 19:176-182. https://doi.org/10.1016/j.jtos.202 0.05 .011
4. Chen L, Liu M, Zhang Z, Qiao K, Huang T, Chen M, Xin N, Huang Z, Liu L, Zhang G, Wang J (2020) Ocular manifestations of a hospitalised patient with confirmed 2019 novel coronavirus disease. Br J Ophthalmol 104(6):748-751. https://doi.org/10.1136/bjophthalmol-2020-316304

5. Xia J, Tong J, Liu M, Shen Y, Guo D (2020) Evaluation of coronavirus in tears and conjunctival secretions of patients with SARS-CoV-2 infection. J Med Virol 92(6):589-594. https://doi.org/10.1002/jmv.25725

6. Sawant OB, Singh S, Wright RE et al (2021) Prevalence of SARS-CoV-2 in human post-mortem ocular tissues. Ocul Surf 19:322-329. https://doi.org/1 0.1016/j.jtos.2020.11.002

7. Kumar K, Prakash AA, Gangasagara SB, Rathod SBL, Ravi K, Rangaiah A, Shankar SM, Basawarajappa SG, Bhushan S, Neeraja TG, Khandenahalli S, Swetha M, Gupta P, Sampritha UC, Prasad GNS, Jayanthi CR (2020) Presence of viral RNA of SARS-CoV-2 in conjunctival swab specimens of COVID-19 patients. Indian J Ophthalmol 68:1015-1017. https://doi.org/10.4103/ijo. IJO_ 1287_20, 6

8. Güemes-Villahoz N, Burgos-Blasco B, Arribi-Vilela A, Arriola-Villalobos P, RicoLuna CM, Cuiña-Sardiña R, Delgado-Iribarren A, García-Feijoó J (2021) Detecting SARS-CoV-2 RNA in conjunctival secretions: is it a valuable diagnostic method of COVID-19? J Med Virol 93(1):383-388. https://doi. org/10.1002/jmv.26219

9. Zhou L, Xu Z, Castiglione GM, Soiberman US, Eberhart CG, Duh EJ (2020) ACE2 and TMPRSS2 are expressed on the human ocular surface, suggesting susceptibility to SARS-CoV-2 infection. Ocul Surf 18(4):537-544. https://doi. org/10.1016/j.jtos.2020.06.007

10. Raboud J, Shigayeva A, McGeer A, Bontovics E, Chapman M, Gravel D, Henry B, Lapinsky S, Loeb M, McDonald LC, Ofner M, Paton S, Reynolds D, Scales D, Shen S, Simor A, Stewart T, Vearncombe M, Zoutman D, Green K (2010) Risk factors for SARS transmission from patients requiring intubation: a multicentre investigation in Toronto, Canada. PLoS One 5(5):e10717. https:// doi.org/10.1371/journal.pone.0010717

11. Wan Y, Shang J, Graham R, Baric RS, Li F (2020) Receptor recognition by the novel coronavirus from Wuhan: an analysis based on decade-long structural studies of SARS coronavirus. J Virol 94(7). https://doi.org/10.1128/JVI.00127-2 0

12. Ozturker ZK (2021) Conjunctivitis as sole symptom of COVID-19: a case report and review of literature. Eur J Ophthalmol 31(2):NP161-NP166. https://doi.org/10.1177/1120672120946287

13. Ulhaq ZS, Soraya GV (2020) The prevalence of ophthalmic manifestations in COVID-19 and the diagnostic value of ocular tissue/fluid. Graefes Arch Clin Exp Ophthalmol 258(6):1351-1352. https://doi.org/10.1007/s00417-020-04 695-8

14. Zhou Y, Duan C, Zeng Y, Tong Y, Nie Y, Yang Y, Chen Z, Chen C (2020) Ocular findings and proportion with conjunctival SARS-COV-2 in COVID-19 patients. Ophthalmology 127(7):982-983. https://doi.org/10.1016/j.ophtha.2 020.04.028

15. Nasiri N, Sharifi H, Bazrafshan A, Noori A, Karamouzian M, Sharifi A (2021) Ocular manifestations of COVID-19: a systematic review and Meta-analysis. J Ophthalmic Vis Res 16(1):103-112. https://doi.org/10.1 8502/jovr.v16i1.8256

16. Jones L, Walsh K, Willcox M, Morgan P, Nichols J (2020) The COVID-19 pandemic: important considerations for contact lens practitioners. Contact Lens Anterior Eye 43(3):196-203. https://doi.org/10.1016/j.clae.2020.03.012

17. Lai TH, Tang EW, Chau SK et al (2020) Stepping up infection control measures in ophthalmology during the novel coronavirus outbreak: an experience from Hong Kong. Graefes Arch Clin Exp Ophthalmol 258(5): 1049-1055. https://doi.org/10.1007/s00417-020-04641-8

18. Romano MR, Montericcio A, Montalbano C, Raimondi R, Allegrini D, Ricciardelli G, Angi M, Pagano L, Romano V (2020) Facing COVID-19 in ophthalmology department. Curr Eye Res 45(6):653-658. https://doi.org/10.1 080/02713683.2020.1752737

19. Sadhu S, Agrawal R, Pyare R, Pavesio C, Zierhut M, Khatri A, Smith JR, de Smet MD, Biswas J (2020) COVID-19: limiting the risks for eye care professionals. Ocul Immunol Inflamm 28(5):714-720. https://doi.org/10.1080/ 09273948.2020 .1755442

20. Sengupta S, Honavar SG, Sachdev MS, Sharma N, Kumar A, Ram J, Shetty R, Rao GS, Ramasamy K, Khanna R, Jain E, Bhattacharjee K, Agarwal A, Natarajan S, Lahane TP, Committee W (2020) All India ophthalmological society-Indian journal of ophthalmology consensus statement on preferred practices during the COVID-19 pandemic. Indian J Ophthalmol 68(5):711. https://doi.org/10.4103/ijo.IJO_871_20 
21. Aggarwal K, Agarwal A, Jaiswal N, Dahiya N, Ahuja A, Mahajan S, Tong L, Duggal M, Singh M, Agrawal R, Gupta V (2020) Ocular surface manifestations of coronavirus disease 2019 (COVID-19): a systematic review and meta-analysis. PLoS One 15(11):e0241661. https://doi.org/10.1371/journa I.pone. 0241661

22. Wu P, Duan F, Luo C, Liu Q, Qu X, Liang L, Wu K (2020) Characteristics of ocular findings of patients with coronavirus disease 2019 (COVID-19) in Hubei Province, China. JAMA Ophthalmol 138(5):575-578. https://doi.org/1 0.1001/jamaophthalmol.2020.1291

23. Shimmura S, Shimazaki J, Tsubota K (1999) Results of a population-based questionnaire on the symptoms and lifestyles associated with dry eye. Cornea 18(4):408-411. https://doi.org/10.1097/00003226-199907000-00003

24. Marinho PM, Marcos AA, Romano AC et al (2020) Retinal findings in patients with COVID-19. Lancet 395(10237):1610. https://doi.org/10.1016/S0140-673 6(20)31014-X

25. Tostmann A, Bradley J, Bousema T, Yiek WK, Holwerda M, Bleeker-Rovers C, ten Oever J, Meijer C, Rahamat-Langendoen J, Hopman J, van der GeestBlankert N, Wertheim H (2020) Strong associations and moderate predictive value of early symptoms for SARS-CoV-2 test positivity among healthcare workers, the Netherlands, march 2020. Eurosurveillance 25(16):2000508. https://doi.org/10.2807/1560-7917.ES.2020.25.16.2000508

26. Zhang X, Chen X, Chen L, Deng C, Zou X, Liu W, Yu H, Chen B, Sun X (2020) The evidence of SARS-CoV-2 infection on ocular surface. Ocul Surf 18(3): 360-362. https://doi.org/10.1016/j.jtos.2020.03.010

27. Jin Y-P, Trope GE, El-Defrawy S et al (2021) Ophthalmology-focused publications and findings on COVID-19: a systematic review. Eur J Ophthalmol 31(4):1677-1687. https://doi.org/10.1177/1120672121992949

\section{Publisher's Note}

Springer Nature remains neutral with regard to jurisdictional claims in published maps and institutional affiliations.

\section{Submit your manuscript to a SpringerOpen ${ }^{\circ}$ journal and benefit from:}

- Convenient online submission

- Rigorous peer review

- Open access: articles freely available online

- High visibility within the field

- Retaining the copyright to your article 